\title{
A fuzzy multi-objective approach for a meat supply chain design
}

\author{
Ahmed Mohammed \\ School of Engineering. University of Portsmouth \\ Portsmouth, UK \\ Ahmed.mohammed@port.ac.uk
}

\author{
Qian Wang \\ School of Engineering. University of Portsmouth \\ Portsmouth, UK \\ Qian.wang@port.ac.uk
}

\begin{abstract}
The global demand of food may be doubled by 2050 making food supply chains as one of the largest sectors in economy. Thus, a robust design of a food supply chain network is essential for a success in a competitive market and this has been increasingly becoming one of major issues for decision makers in supply chain sectors. This article presents a multi-objective model for solving an issue of a three-echelon meat supply chain (MSC) design and its distribution problem. The objectives of the developed model are aimed at minimizing the total transportation cost and $\mathrm{CO}_{2}$ emissions, and maximizing the average delivery rate in satisfying product quantity as requested by abattoirs and retailers. Furthermore, the model is formulated in terms of a fuzzy multi-objective linear programming model (FMOLPM) to handle the uncertainties associated with costs and demands in product quantity within the considered MSC. To optimize the three objectives under varying conditions, two solution methods were investigated and used. These include the method of LP-metrics and the method of E-constraint in order to compare the obtained Pareto solutions. The best solution was determined using the Max-Min method. Computational results demonstrate the effectiveness of the developed model that helps tackle a number of issues for a meat supply chain design.
\end{abstract}

Keywords-Supply chain; Fuzzy; Distribution plan; Environmental impact.

\section{INTRODUCTION}

The global demand of food may be doubled by 2050 making food supply chains (FSC) as one of the largest sectors in economy [1]. Thus, a robust design of food supply chain network is essential for a success in a competitive market and it has been increasingly becoming one of major issues for decision makers in supply chain sectors. One of supply chain design tasks involves a determination in location and allocation of facilities and quantity flow of products travelling throughout the supply chain network. Today, environmental issues are equally important and should be taken into account when designing a supply chain network, it may be essential to consider the possibility of incorporating environmental considerations into design of supply chain networks [2]. Issues of uncertainty need also to be taken into account when designing a supply chain network. A number of researchers applied fuzzy multi-objective optimization methods to tackle the randomness as input data of supply chain networks.

There are a few publications in research using multiobjective optimization in the context of FSC management.
Rong [3] developed a mixed integer linear programming model for solving a production and distribution planning problem of a food supply chain. Sahar [4] proposed a multiobjective optimization model of a two-layer dairy supply chain aiming to minimize $\mathrm{CO}_{2}$ emissions of transportation and the total cost for product distribution.

More attention focused on the provision of fuzzy programming techniques in the context of dealing with problems of supply chain network design and distribution. Snyder [5] reviewed supply chain planning-distribution issues in data uncertainty. Zarandi [6] used the interactive fuzzy goal programming model in order to solve the network design problem of a closed-loop supply chain. Liu [7] addressed issues in production, distribution and capacity planning of a global supply chain and developed a multi-objective mixedinteger linear programming approach to investigate three objectives: the total cost, the total flow time and total lost sales. Kannan [8] proposed an approach to rank and select the green suppliers of a supply chain according to economic and environmental criteria and then allocate the optimum order quantities among them. The proposed approach was a combination of the fuzzy multi-attribute utility theory and multi-objective programming. Mohammed [9] developed a multi-objective possibilistic programming approach for designing a supply chain network. Peidro [10] presented a fuzzy mono-objective mixed-integer linear programming model for supply chain tactical planning in which the total cost was to be minimized.

This paper presents a study in developing a FMOLPM of a three-echelon meat supply chain. The model can be used for supporting design decisions towards the optimization of three objectives; these include the minimization of total transportation cost and $\mathrm{CO}_{2}$ emissions, and the maximization of average delivery rate.

\section{PROBLEM DESCRIPTION AND MODEL FORMULATION}

In this work, a FMOLPM was developed for a threeechelon meat supply chain network consisting of farms, abattoirs and retailers. Fig. 1 depicts the structure of the threeechelon meat supply chain network. An RFID-enabled monitoring system was introduced to monitor safety of freshness of meats sold to supermarkets. Such a monitoring system is subject to additional costs in investments that need to be taken into account when designing the meat supply chain 
as well as distribution decisions. The FMOLPM was used for optimising (i) the number and locations of farms and abattoirs that should be opened to the proposed supply chain and (ii) the optimum quantity of product flows between farms and abattoirs and between abattoirs and retailers. The following sets, parameters and decision variables were used:

Sets

$E$ set of farms $(1 \ldots e \ldots E)$

$F$ set abattoirs $(1 \ldots$ f... F)

$G$ set retailers $(1 \ldots \mathrm{g} \ldots \mathrm{G})$

\section{Parameters}

$C_{e f}^{t} \quad$ RFID tag cost (GBP) per item transported from farm $e$ to abattoir $f$

$C_{f g}^{t} \quad$ RFID tag cost (GBP) per item transported from abattoir $f$ to retailer $g$

$C_{e f}^{m / l} \quad$ RFID reader cost (GBP) required per lorry $l$ travelling from farm $i$ to abattoir $j$

$C_{f g}^{m / l} \quad$ RFID reader cost (GBP) required per lorry $l$ travelling from abattoir $f$ to retailer $g$

$T C_{e f}$ unit transportation cost (GBP) per mile from farm $e$ to abattoir $f$

$T C_{f g}$ unit transportation cost (GBP) per mile from abattoir $f$ to retailer $g$

$C_{e}^{h}$ handling cost per livestock at farms $e$

$C_{f}^{h}$ handling cost per meat piece at abattoir $f$

$d_{e f}$ transportation distance (mile) of livestock from farm $e$ to abattoir $f$

$d_{f g} \quad$ transportation distance (mile) of processed meats

from abattoir $f$ to retailer $g$

$C_{l} \quad$ transportation capacity (units) per lorry $l$

$C_{e} \quad$ maximum supply capacity (units) of farm $e$

$C_{f}$ maximum supply capacity (units) of abattoir $f$

$\mathrm{D}_{f}$ minimum demand (in units) of abattoir $f$

$\mathrm{D}_{g}$ minimum demand (in units) of retailer $g$

$\mathrm{CO}_{2 e f} \mathrm{CO}_{2}$ emission in gram per mile for each vehicle travelled from farm $e$ to abattoir $f$

$\mathrm{CO}_{2 f g} \quad \mathrm{CO}_{2}$ emission in gram per mile for each vehicle travelled from abattoir $f$ to retailer $g$

Decision variables

$m_{e f}$ quantity of livestock transported from farm $e$ to abattoir $f$

$m_{f g}$ quantity of processed meats transported from abattoir

$f$ to retailer $g$

Binary decision variables

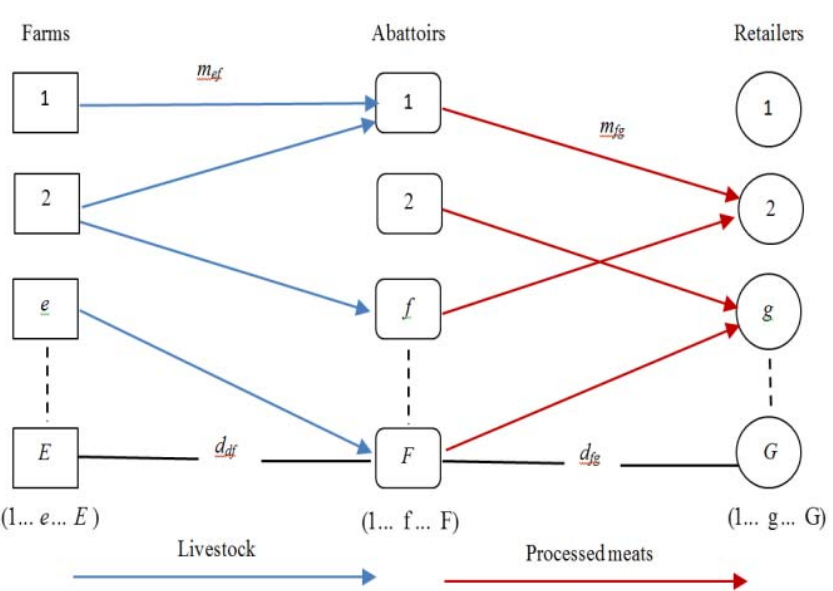

Fig. 1. The three-echelon meat supply chain network.

$u_{e}=\left\{\begin{array}{l}1: \text { if farm } e \text { is open } \\ 0: \text { otherwise }\end{array}\right.$

$v_{f}=\left\{\begin{array}{l}1: \text { if abattoir } f \text { is open } \\ 0: \text { otherwise }\end{array}\right.$

Three conflicting objectives, which include the minimization of the total transportation $\cos t \mathrm{Z}_{1}$, minimization of the $\mathrm{CO}_{2}$ emissions $\mathrm{Z}_{2}$ and maximization of the average delivery rate $Z_{3}$, can be defined as objective functions below:

$$
\begin{aligned}
& \text { Min } Z_{1}=\sum_{e \in E} \sum_{f \in F} T C_{e f}\left\lceil\frac{m_{e f}}{W_{l}}\right\rceil d_{e f}+\sum_{f \in F} \sum_{g \in G} T C_{f g}\left\lceil\frac{m_{f g}}{W_{l}}\right\rceil d_{f g} \\
& +\sum_{e \in E} \sum_{f \in F} C_{e}^{d} m_{e f}+\sum_{f \in F} \sum_{g \in G} C_{f}^{d} m_{f g}+\sum_{e \in E} \sum_{f \in F} C_{e f}^{t} m_{e f}+\sum_{f \in F} \sum_{g \in G} C_{f g}^{t} m_{f g} \\
& +\sum_{e \in E} \sum_{f \in F} C_{e f}^{m / l}\left\lceil\frac{m_{e f}}{W_{l}}\right\rceil+\sum_{f \in F} \sum_{g \in G} C_{f g}^{m / l}\left\lceil\frac{m_{f g}}{W_{l}}\right\rceil \\
& \operatorname{Min} Z_{2}=\sum_{e \in E} \sum_{f \in F} C O_{2 e f}\left\lceil\frac{m_{e f}}{W_{l}}\right\rceil d_{e f}+\sum_{f \in F} \sum_{g \in G} C O_{2 f g}\left\lceil\frac{m_{f g}}{W_{l}}\right\rceil d_{f g}
\end{aligned}
$$

$$
\operatorname{Max}_{3}=\frac{\sum_{f \in F}\left(\sum_{e \in E} m_{e f} / D_{f}\right)+\sum_{g \in G}\left(\sum_{f \in F} m_{f g} / D_{g}\right)}{2}
$$

s.t.

$$
\begin{array}{ll}
\sum_{e \in E} m_{e f} \leq C_{e} \mathrm{u}_{e} & \forall \mathrm{f} \in F \\
\sum_{f \in F} m_{f g} \leq C_{f} \mathrm{v}_{f} & \forall \mathrm{g} \in G \\
\sum_{e \in E} m_{e f} \geq \mathrm{D}_{f} & \forall \mathrm{f} \in F \\
\sum_{f \in F} m_{f g} \geq \mathrm{D}_{g} & \forall \mathrm{g} \in G
\end{array}
$$




$$
\begin{gathered}
\mathrm{D}_{f} \geq \sum_{g \in G} m_{f g} \quad \forall \mathrm{f} \in F \\
m_{e f}, m_{f g} \geq 0 \quad \forall e \\
u_{e}, v_{f} \in\{1,0\}, \quad \forall e, f
\end{gathered}
$$

Where, for Eq. 1 it minimizes the total transportation cost which includes the transportation cost in the meat supply chain, the handling cost at farms and abattoirs, the RFID-tag cost for each item and the RFID reader cost required for each transportation vehicle. For Eq. 2 it minimizes the amount of $\mathrm{CO}_{2}$ emissions throughout the two-level transportation routes from farms to abattoirs and from abattoirs to retailers. For Eq. 3 it maximizes the average delivery rate. For Eq. 4 it limits the amount of livestock shipped from farms to abattoirs so that it cannot exceed the full capacity of farms. For Eq. 5 it ensures the flow of meat products from abattoirs to retailer does not exceed the full capacity of abattoirs. For Equations 6-8 these maintain the flow of product quantity between farms and abattoirs and between abattoirs and retailers. For equations 9 and10 it limits the non-binary and non-negativity restrictions on decision variables.

\section{A. Modeling the uncertainty}

In this work, a fuzzy multi-objective programming model was developed to incorporate parameters of the meat supply chain including costs and demands which were considered as uncertain parameters. To this aim, the multi-objective programming model was transformed to a crisp model using an approach proposed by Jiménez López [11]. Based on Jiménez's approach, the equivalent crisp model is expressed as follows:

$$
\begin{aligned}
& \operatorname{Min} Z_{1}=\sum_{e \in E} \sum_{f \in F}\left(\frac{T C_{e f}^{\text {pes }}+2 T C_{e f}^{\text {mos }}+T C_{e f}^{\text {opt }}}{4}\right)\left\lceil\frac{m_{e f}}{W_{l}}\right] d_{e f} \\
& +\sum_{f \in F g \in G}\left(\frac{T C_{f g}^{p e s}+2 T C_{f g}^{m o s}+T C_{f g}^{o p t}}{4}\right)\left[\frac{m_{f g}}{W_{l}}\right] d_{f g} \\
& +\sum_{e \in E} \sum_{F \in f}\left(\frac{C_{e}^{\text {dpes }}+2 C_{e}^{\text {dimos }}+C_{e}^{\text {dopt }}}{4}\right) m_{e f}+\sum_{f \in F} \sum\left(\frac{C_{f}^{\text {dpes }}+2 C_{f}^{\text {dmos }}+C_{f}^{\text {dopt }}}{4}\right) m_{f g} \\
& +\sum_{e \in E} \sum_{f \in F}\left(\frac{C_{e f}^{\text {tpes }}+2 C_{e f}^{\text {tmos }}+C_{e f}^{\text {topt }}}{4}\right) m_{e f}+\sum_{f \in F} \sum_{g \in G}\left(\frac{C_{f g}^{\text {tpes }}+2 C_{f g}^{\text {thmos }}+C_{f g}^{\text {topt }}}{4}\right) m_{f g}
\end{aligned}
$$

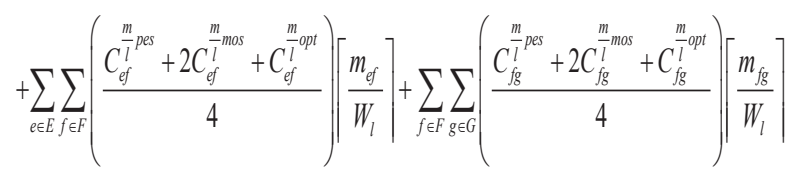

$\operatorname{Min} Z_{2}=\sum_{e \in E} \sum_{f \in F} C O_{2 e f}\left\lceil\frac{m_{e f}}{W_{l}}\right\rceil d_{e f}+\sum_{f \in F} \sum_{g \in G} C O_{2 f g}\left\lceil\frac{m_{f g}}{W_{l}}\right\rceil d_{f g}^{(12)}$

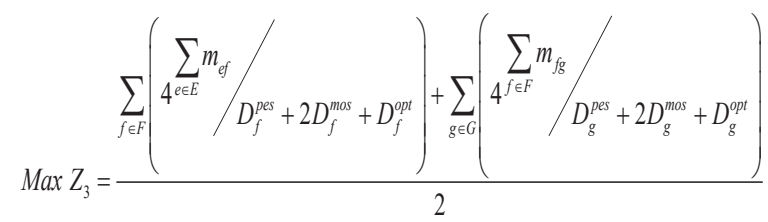

s.t.

$$
\begin{gathered}
\sum_{e \in E} m_{e f} \leq C_{e} \mathrm{u}_{e}, \quad \forall \mathrm{f} \in F \\
\sum_{f \in F} m_{e f} \leq C_{f} \mathrm{v}_{f}, \quad \forall \mathrm{g} \in G \\
\sum_{e \in E} m_{e f} \geq\left[\frac{\alpha}{2} \cdot \frac{\mathrm{D}_{f 1}+\mathrm{D}_{f 2}}{2}+\left(1-\frac{\alpha}{2}\right) \frac{\mathrm{D}_{f 3}+\mathrm{D}_{f 4}}{2}\right], \quad \forall \mathrm{f} \in F \\
\sum_{f \in F} m_{f g} \geq\left[\frac{\alpha}{2} \cdot \frac{\mathrm{D}_{g 1}+\mathrm{D}_{g 2}}{2}+\left(1-\frac{\alpha}{2}\right) \frac{\mathrm{D}_{g 3}+\mathrm{D}_{g 4}}{2}\right], \quad \forall \mathrm{g} \in G \\
{\left[\frac{\alpha}{2} \cdot \frac{\mathrm{D}_{f 1}+\mathrm{D}_{f 2}}{2}+\left(1-\frac{\alpha}{2}\right) \frac{\mathrm{D}_{f 3}+\mathrm{D}_{f 4}}{2}\right] \geq \sum_{g \in G} m_{f g}, \quad \forall \mathrm{f} \in F} \\
m_{e f}, m_{f g} \geq 0 \quad \forall e, f \\
u_{e}, v_{f}, \alpha \in\{1,0\}, \quad \forall e, f
\end{gathered}
$$

According to the Jiménez's approach, it is supposed that the fuzzy constraints in the model should be satisfied with a confidence value which is denoted as $\alpha$ and it is normally determined by decision makers.

\section{OPTIMIZATION METHODOLOGY}

The developed FMOLPM was proposed to be optimized using the flowing steps:

Step 1: Determine the maximum bound and minimum bound (Max, Min) for each objective function as follows:

For the Max bound solution:

$$
\begin{aligned}
& \operatorname{Max} Z_{1}\left(\operatorname{Max} x_{1}\right)=\sum_{e \in E} \sum_{f \in F} T C_{e f}\left\lceil\frac{m_{e f}}{W_{l}}\right\rceil d_{e f}+\sum_{f \in F} \sum_{g \in G} T C_{f g}\left\lceil\frac{m_{f g}}{W_{l}}\right\rceil d_{f g} \\
& +\sum_{e \in E} \sum_{f \in F} C_{e}^{d} m_{e f}+\sum_{f \in F} \sum_{g \in G} C_{f}^{d} m_{f g}+\sum_{e \in E} \sum_{f \in F} C_{e f}^{t} m_{e f}+\sum_{f \in F} \sum_{g \in G} C_{f g}^{t} m_{f g} \\
& +\sum_{e \in E} \sum_{f \in F} C_{e f}^{m / l}\left\lceil\frac{m_{e f}}{W_{l}}\right\rceil+\sum_{f \in F} \sum_{g \in G} C_{f g}^{m / l}\left\lceil\frac{m_{f g}}{W_{l}}\right\rceil
\end{aligned}
$$$$
\operatorname{Max} Z_{2}\left(\operatorname{Max}_{2}\right)=\sum_{e \in E} \sum_{f \in F} C O_{2 e f}\left\lceil\frac{m_{e f}}{W_{l}}\right\rceil d_{e f}+\sum_{f \in F} \sum_{g \in G} C O_{2 f g}\left\lceil\frac{m_{f g}}{W_{l}}\right\rceil d_{f g}
$$

$$
\operatorname{Max} Z_{3}\left(\operatorname{Max}_{3}\right)=\frac{\sum_{f \in F}\left(\sum_{e \in E} m_{e f} / D_{f}\right)+\sum_{g \in G}\left(\sum_{f \in F} m_{f g} / D_{g}\right)}{2}
$$


$\operatorname{Min} Z_{1}\left(\operatorname{Min}_{1}\right)=\sum_{e \in E} \sum_{f \in F} T C_{e f}\left\lceil\frac{m_{e f}}{W_{l}}\right\rceil d_{e f}+\sum_{f \in F} \sum_{g \in G} T C_{f g}\left\lceil\frac{m_{f g}}{W_{l}}\right\rceil d_{f g}$

$+\sum_{e \in E} \sum_{f \in F} C_{e}^{d} m_{e f}+\sum_{f \in F} \sum_{g \in G} C_{f}^{d} m_{f g}+\sum_{e \in E} \sum_{f \in F} C_{e f}^{t} m_{e f}+\sum_{f \in F} \sum_{g \in G} C_{f g}^{t} m_{f g}$

$+\sum_{e \in E} \sum_{f \in F} C_{e f}^{m / l}\left\lceil\frac{m_{e f}}{W_{l}}\right\rceil+\sum_{f \in F} \sum_{g \in G} C_{f g}^{m / l}\left\lceil\frac{m_{f g}}{W_{l}}\right\rceil$

$\operatorname{Min} Z_{2}\left(\operatorname{Min}_{2}\right)=\sum_{e \in E} \sum_{f \in F} C O_{2 e f}\left\lceil\frac{m_{e f}}{W_{l}}\right\rceil d_{e f}+\sum_{f \in F} \sum_{g \in G} C O_{2 f g}\left\lceil\frac{m_{f g}}{W_{l}}\right\rceil d_{f g}$

$\operatorname{Min} Z_{3}\left(\operatorname{Min}_{3}\right)=\frac{\sum_{f \in F}\left(\sum_{e \in E} m_{e f} / D_{f}\right)+\sum_{g \in G}\left(\sum_{f \in F} m_{f g} / D_{g}\right)}{2}$

Step 2: Each objective function corresponds to an equivalent linear membership function as follows:

$$
\mu(Z(x))= \begin{cases}1 & \text { if } Z(x) \leq \operatorname{Max} \\ \frac{\operatorname{Min}-Z(x)}{\operatorname{Min}-\operatorname{Max}} & \text { if } \operatorname{Min} \leq Z(x) \leq \operatorname{Max} \\ 0 & \text { if } \mathrm{Z}(x) \geq \operatorname{Min}\end{cases}
$$

Where Eq. (27) indicates the satisfaction degree of the three objective functions.

Step 3: Solve the crisp FMOLPM obtained from section II.A by transforming it to a mono-objective model using the proposed solution methods described in section III.A.

Step 4: Use the Max-Min method (described in section III.A) to select the best Pareto solution.

\section{A. Solution methods}

1) LP-metrics: In the LP-metrics method, each objective function needs to be optimized individually. This aims at obtaining the ideal objective values (i.e., $Z_{1}^{*}, Z_{2}^{*}$ and $Z_{3}^{*}$ ). Subsequently, the FMOLPM is solved as a single objective model using the following formula:

Min $\mathrm{Z}=\left[w_{1} \frac{Z_{1}-Z_{1}^{*}}{Z_{1}^{*}}+w_{2} \frac{Z_{2}-Z_{2}^{*}}{Z_{2}^{*}}+w_{3} \frac{Z_{3}-Z_{3}^{*}}{Z_{3}^{*}}\right]$

Subject to Eq. (14-20).

2) $\varepsilon$-constraint: In the $\varepsilon$-constraint method, the FMOLPM turns into a single-objective model by keeping the most important function as an objective function, and considering other functions as the $\varepsilon$-based constraints. Thus, the equivalent solution formula $(Z)$ is given by:

$$
\operatorname{Min} Z=\operatorname{Min} Z_{1}
$$

s.t.

$$
\begin{gathered}
Z_{2} \leq \varepsilon_{1} \\
{\left[Z_{2}\right]^{\text {min }} \leq \varepsilon_{1} \leq\left[Z_{2}\right]^{\text {max }}}
\end{gathered}
$$

$$
\begin{gathered}
Z_{3} \geq \varepsilon_{2} \\
{\left[Z_{3}\right]^{\min } \leq \varepsilon_{2} \leq\left[Z_{3}\right]^{\max }}
\end{gathered}
$$

And Eq. (14-20).

3)Max-Min: In this work, the Max-Min method was used to select the best trade-off $(B T)$ solution. Accordingly, the selection formula is expressed as follows:

$$
B T=\sum_{i=1}^{3} \frac{Z_{i}}{Z_{i}^{*}}
$$

\section{IMPLEMENTATION AND EVALUATION}

In this section, a case study was used for evaluating the applicability of the developed FMOLPM and the performance of the proposed optimization methodology. Table I shows the relevant parameters and their values used for the case study. Data, which are associated with locations of farms, abattoirs and retailers, were collected from the Meat Committee in the UK [12]. The Google Map was used to estimate travelling distances in locations between farms, abattoirs and retailers in the South-West of London. The developed model was coded using the LINGO ${ }^{11}$ optimization software.

First, the Max and Min bounds for the three objectives needed to be determined. To this aim, Eq. 21-26 were applied. Table II shows the obtained results relating to $Z_{1}, Z_{2}$ and $Z_{3}$. For instance, $Z_{1}\{\operatorname{Max}, \operatorname{Min}\}=\{195,400,43,540\}$. These values were used to obtain the membership functions for each objective.

To minimize the total transportation cost and $\mathrm{CO}_{2}$ emissions and maximize the average delivery rate, the two solution methods previously described were implemented as follows:

1) LP-metrics: each objective function was optimized independently under the predefined constraints. The results are reported in Table III, which shows, for instance, by optimizing the first objective $Z_{1}$ individually, it gives the result as $Z_{1}=$ 43540, $Z_{2}=63520.09$ and $Z_{3}=0.77$. The possible ideal values for the objective functions are boldfaced in the Table: $Z_{1}=$ $43540, Z_{2}=6347.65$ and $Z_{3}=0.98$. Then, the Pareto solutions of the FMOLPM were obtained based on the determination of weights of the objective functions. Table IV shows the varying computational results in response to one of ten different values of weight for each of the three objectives.

Table I The values of parameters used for the case study

\begin{tabular}{cccc}
\hline Parameter & Values & Parameter & Values \\
\hline$T C_{e f}$ & $(15,18)$ & $D_{g}$ & $(1400,1500)$ \\
$T C_{f g}$ & $(15,18)$ & $C_{e}$ & $(1500,1800)$ \\
$C_{e f}^{t}$ & $(0.15,0.18)$ & $C_{f}$ & $(1700,2000)$ \\
$C_{f g}^{t}$ & $(0.15,0.18)$ & $C_{l}$ & $(20,31)$ \\
$C_{e f}^{m / l}$ & $(800,950)$ & $d_{e f}$ & $(43,210)$ \\
$C_{f}^{m / l}$ & $(800,950)$ & $d_{f g}$ & $(110,174)$ \\
$C_{e}^{d}$ & $(3.5,4)$ & $C O_{2 e f}$ & $(271,294)$ \\
$C_{f}^{d}$ & $\sim(3.5,4)$ & $C O_{2 f g}$ & $\sim(271,294)$ \\
$D_{f}$ & & $\sim(2200,3000)$ & \\
\hline
\end{tabular}


Table II The Max and Min values in responding to objective $Z_{1}, Z_{2}$ and $Z_{3}$,

\begin{tabular}{ccc} 
& respectively & Min \\
\hline Objective functions & Max & \\
\hline$Z_{1}$ & 195400 & 43540 \\
$Z_{2}$ & 27215.48 & 6347.65 \\
$Z_{3}$ & 0.98 & 0.76 \\
\hline
\end{tabular}

2) $\varepsilon$-constraints: as the maximum value and minimum value for each objective can be obtained by Eq. 21-26, the range between these two values was divided into ten segments, the grid points ( $\varepsilon$-points) in between were assigned as $\varepsilon$ values in Eq. 30 and 32 and the Pareto solutions were obtained by Eq. 29. The total transportation cost is considered as an objective function, whilst the objectives of $\mathrm{CO}_{2}$ emissions and average delivery rate are considered as constraints. Table V shows the computational results based on the FMOLPM under ten $\varepsilon$-iterations. It can be seen that the two methods were applied, respectively, with ten $\alpha$ levels $(0.1$, $0.2,0.3,0.4,0.5,0.6,0.7,0.8,0.9$ and 1 ).
Table III Values of $Z_{1}, Z_{2}$ and $Z_{3}$ obtained by optimizing them

\begin{tabular}{cccc}
\hline \multicolumn{4}{c}{ individually } \\
\hline Objective functions & Min $\mathbf{Z}_{1}$ & Min $\mathbf{Z}_{2}$ & Max $\mathbf{Z}_{3}$ \\
\hline$Z_{1}$ & $\mathbf{4 3 5 4 0}$ & 44670 & 195380 \\
$Z_{2}$ & 63520.09 & $\mathbf{6 3 4 7 . 6 5}$ & 26490.27 \\
$Z_{3}$ & 0.77 & 0.76 & $\mathbf{0 . 9 8}$ \\
\hline
\end{tabular}

By setting these ten levels to the $\alpha$, with steps 0.1 and implementing it to the model, ten Pareto solutions were obtained. Therefore, the model should be frequently solved for each $\alpha$ level.

As shown in Tables IV and $\mathrm{V}$, the results are also associated with numbers and geographical locations of farms and abattoirs that should be opened to the proposed supply chain network. For an example, solution 1 in Table $\mathrm{V}$ has two opened farms, which are located in Warwick and Leicester, to supply livestock to two abattoirs located in Birmingham and Balham. The solution leads to a transportation cost of 435,40 GBP, $\mathrm{CO}_{2}$ emissions of $6349.73 \mathrm{~kg}$ and an average delivery rate of $76.6 \%$. It can be seen in these tables that increasing the desired value of $Z_{3}$ leads to

Table IV. Computational results of $Z_{1}, Z_{2}$ and $Z_{3}$ obtained using the LP-metrics method

\begin{tabular}{|c|c|c|c|c|c|c|c|c|c|}
\hline$\#$ & $\left(\mathbf{W}_{1}, \mathbf{W}_{2}, \mathbf{W}_{3}\right)$ & $\mu_{1}\left(Z_{1}\right)$ & $\mu_{2}\left(Z_{2}\right)$ & $\mu_{3}\left(Z_{3}\right)$ & $\begin{array}{c}\operatorname{Min} Z_{1} \\
(G B P)\end{array}$ & $\begin{array}{c}\operatorname{Min} Z_{2} \\
(\mathrm{Kg})\end{array}$ & $\begin{array}{c}\operatorname{Max} Z_{3} \\
(\%)\end{array}$ & Farms & Abattoirs \\
\hline 1 & $1,0,0$ & 0.98 & 0.95 & 0.01 & 43540 & 6349.73 & 0.766 & $\begin{array}{l}\text { (3)Warwick } \\
\text { (5)Leicester }\end{array}$ & $\begin{array}{l}\text { (3) Birmingham } \\
\text { (4)Balham }\end{array}$ \\
\hline 2 & $0.9,0.05,0.05$ & 0.85 & 0.83 & 0.11 & 43540 & 6349.73 & 0.766 & $\begin{array}{l}\text { (3)Warwick } \\
\text { (5)Leicester }\end{array}$ & $\begin{array}{l}\text { (3) Birmingham } \\
\text { (4)Balham }\end{array}$ \\
\hline 3 & $0.8,0.1,0.1$ & 0.68 & 0.78 & 0.22 & 73271 & 8572.34 & 0.811 & $\begin{array}{l}\text { (2)Warwick } \\
\text { (3)Warwick } \\
\text { (5)Leicester }\end{array}$ & $\begin{array}{l}\text { (2) West Midland } \\
\text { (3) Birmingham } \\
\text { (4)Balham }\end{array}$ \\
\hline 4 & $0.7,0.15,0.15$ & 0.78 & 0.65 & 0.32 & 85521 & 11094.55 & 0.855 & $\begin{array}{l}\text { (2)Warwick } \\
\text { (3)Warwick } \\
\text { (5)Leicester }\end{array}$ & $\begin{array}{l}\text { (2) West Midland } \\
\text { (3) Birmingham } \\
\text { (5) Norfolk }\end{array}$ \\
\hline 5 & $0.6,0.2,0.2$ & 0.61 & 0.5 & 0.43 & 99507 & 13594.31 & 0.888 & $\begin{array}{l}\text { (2)Warwick } \\
\text { (3)Warwick } \\
\text { (5)Leicester }\end{array}$ & $\begin{array}{l}\text { (1) Warrick } \\
\text { (3) Birmingham } \\
\text { (4)Balham }\end{array}$ \\
\hline 6 & $0.5,0.25,0.25$ & 0.48 & 0.47 & 0.55 & 114472 & 16118.87 & 0.9 & $\begin{array}{l}\text { (2)Warwick } \\
\text { (3)Warwick } \\
\text { (5)Leicester }\end{array}$ & $\begin{array}{l}\text { (2) West Midland } \\
\text { (3) Birmingham } \\
\text { (4) Balham } \\
\text { (5) Norfolk }\end{array}$ \\
\hline 7 & $0.45,0.3,0.25$ & 0.31 & 0.35 & 0.66 & 127498 & 18657 & 0.922 & $\begin{array}{l}\text { (2)Warwick } \\
\text { (3)Warwick } \\
\text { (4)Yorkshire } \\
\text { (5)Leicester }\end{array}$ & $\begin{array}{l}\text { (1) Warrick } \\
\text { (3) Birmingham } \\
\text { (4) Balham } \\
\text { (5) Norfolk }\end{array}$ \\
\hline 8 & $0.4,0.3,0.3$ & 0.28 & 0.25 & 0.74 & 144388 & 21077 & 0.944 & $\begin{array}{l}\text { (1)Yorkshire } \\
\text { (2)Warwick } \\
\text { (3)Warwick } \\
\text { (4)Yorkshire } \\
\text { (5)Leicester }\end{array}$ & $\begin{array}{l}\text { (1) Warrick } \\
\text { (2) West Midland } \\
\text { (3) Birmingham } \\
\text { (4) Balham } \\
\text { (5) Norfolk }\end{array}$ \\
\hline 9 & $0.3,0.35,0.35$ & 0.2 & 0.17 & 0.88 & 172680 & 23729 & 0.977 & $\begin{array}{l}\text { (1)Yorkshire } \\
\text { (2)Warwick } \\
\text { (3)Warwick } \\
\text { (4)Yorkshire } \\
\text { (5)Leicester }\end{array}$ & $\begin{array}{l}\text { (1) Warrick } \\
\text { (2) West Midland } \\
\text { (3) Birmingham } \\
\text { (4) Balham } \\
\text { (5) Norfolk }\end{array}$ \\
\hline 10 & $0.35,0.3,0.35$ & 0.09 & 0.1 & 0.98 & 194231 & 26800.17 & 0.977 & $\begin{array}{l}\text { (1)Yorkshire } \\
\text { (2)Warwick } \\
\text { (3)Warwick } \\
\text { (4)Yorkshire } \\
\text { (5)Leicester }\end{array}$ & $\begin{array}{l}\text { (1) Warrick } \\
\text { (2) West Midland } \\
\text { (3) Birmingham } \\
\text { (4) Balham } \\
\text { (5) Norfolk }\end{array}$ \\
\hline
\end{tabular}


Table V. Computational results of $Z_{1}, Z_{2}$ and $Z_{3}$ obtained using the $\varepsilon$-constraint approach

\begin{tabular}{|c|c|c|c|c|c|c|c|c|c|c|}
\hline$\#$ & $\varepsilon_{1}$ & $\varepsilon_{2}$ & $\mu_{1}\left(Z_{1}\right)$ & $\mu_{2}\left(Z_{2}\right)$ & $\mu_{3}\left(Z_{3}\right)$ & $\begin{array}{c}\operatorname{Min} Z_{1} \\
(G B P)\end{array}$ & $\begin{array}{c}\operatorname{Min} \mathrm{Z}_{2} \\
(\mathrm{Kg})\end{array}$ & $\begin{array}{c}\operatorname{Max} Z_{3} \\
(\%)\end{array}$ & Farms & Abattoirs \\
\hline 1 & 6400 & 0.76 & 0.98 & 0.95 & 0.01 & 43540 & 6349.73 & 0.766 & $\begin{array}{l}\text { (3)Warwick } \\
\text { (5)Leicester }\end{array}$ & $\begin{array}{l}\text { (3) Birmingham } \\
\text { (4)Balham }\end{array}$ \\
\hline 2 & 8650 & 0.79 & 0.85 & 0.83 & 0.11 & 43540 & 6349.73 & 0.766 & $\begin{array}{l}\text { (3)Warwick } \\
\text { (5)Leicester }\end{array}$ & $\begin{array}{l}\text { (3) Birmingham } \\
\text { (4)Balham }\end{array}$ \\
\hline 3 & 10900 & 0.82 & 0.64 & 0.72 & 0.25 & 74510 & 8916.81 & 0.82 & $\begin{array}{l}\text { (2)Warwick } \\
\text { (3)Warwick } \\
\text { (5)Leicester }\end{array}$ & $\begin{array}{l}\text { (2) West Midland } \\
\text { (3) Birmingham } \\
\text { (4)Balham }\end{array}$ \\
\hline 4 & 13100 & 0.85 & 0.73 & 0.64 & 036 & 88321 & 11050.22 & 0.855 & $\begin{array}{l}\text { (2)Warwick } \\
\text { (3)Warwick } \\
\text { (5)Leicester }\end{array}$ & $\begin{array}{l}\text { (1) Warrick } \\
\text { (3) Birmingham } \\
\text { (5) Norfolk }\end{array}$ \\
\hline 5 & 15200 & 0.8 & 0.64 & 0.47 & 0.45 & 98398 & 13887.22 & 0.888 & $\begin{array}{l}\text { (2)Warwick } \\
\text { (3)Warwick } \\
\text { (5)Leicester }\end{array}$ & $\begin{array}{l}\text { (1) Warrick } \\
\text { (3) Birmingham } \\
\text { (4)Balham }\end{array}$ \\
\hline 6 & 17400 & 0.9 & 0.45 & 0.44 & 0.56 & 118499 & 16259.11 & 0.9 & $\begin{array}{l}\text { (2)Warwick } \\
\text { (3)Warwick } \\
\text { (4)Yorkshire }\end{array}$ & $\begin{array}{l}\text { (2) West Midland } \\
\text { (3) Birmingham } \\
\text { (4) Balham } \\
\text { (5) Norfolk }\end{array}$ \\
\hline 7 & 19600 & 0.91 & 0.33 & 0.36 & 0.65 & 125293 & 18722.34 & 0.911 & $\begin{array}{l}\text { (2)Warwick } \\
\text { (3)Warwick } \\
\text { (4)Yorkshire } \\
\text { (5)Leicester }\end{array}$ & $\begin{array}{l}\text { (1) Warrick } \\
\text { (3) Birmingham } \\
\text { (4) Balham } \\
\text { (5) Norfolk }\end{array}$ \\
\hline 8 & 21800 & 0.93 & 0.26 & 0.21 & 0.77 & 145591 & 21222.56 & 0.955 & $\begin{array}{l}\text { (1)Yorkshire } \\
\text { (2)Warwick } \\
\text { (3)Warwick } \\
\text { (4)Yorkshire } \\
\text { (5)Leicester }\end{array}$ & $\begin{array}{l}\text { (1) Warrick } \\
\text { (2) West Midland } \\
\text { (3) Birmingham } \\
\text { (4) Balham } \\
\text { (5) Norfolk }\end{array}$ \\
\hline 9 & 25500 & 0.95 & 0.22 & 0.2 & 0.88 & 168591 & 26349.74 & 0.966 & $\begin{array}{l}\text { (1)Yorkshire } \\
\text { (2)Warwick } \\
\text { (3)Warwick } \\
\text { (4)Yorkshire } \\
\text { (5)Leicester }\end{array}$ & $\begin{array}{l}\text { (1) Warrick } \\
\text { (2) West Midland } \\
\text { (3) Birmingham } \\
\text { (4) Balham } \\
\text { (5) Norfolk }\end{array}$ \\
\hline 10 & 27700 & 0.97 & 0.09 & 0.1 & 0.98 & 194992 & 27119.82 & 0.97 & $\begin{array}{l}\text { (1)Yorkshire } \\
\text { (2)Warwick } \\
\text { (3)Warwick } \\
\text { (4)Yorkshire } \\
\text { (5)Leicester }\end{array}$ & $\begin{array}{l}\text { (1) Warrick } \\
\text { (2) West Midland } \\
\text { (3) Birmingham } \\
\text { (4) Balham } \\
\text { (5) Norfolk }\end{array}$ \\
\hline
\end{tabular}

an increase in the undesired values of $Z_{1}$ and $Z_{2}$. The Pareto solutions can be categorized into three sections. In section 1 , solutions 1-3 show a cost-oriented MSC network when the undesired values of $Z_{1}$ and $Z_{2}$ increase modestly i.e. it gives a design of the MSC network with the lower total transportation cost and $\mathrm{CO}_{2}$ emissions. With solutions 4-6 in section 2 it gives a design of the MSC with relatively compromising results of the objective values. In section 3 , it gives a satisfaction-oriented solution (solutions 7-10) design of the MSC with the higher average delivery rate. On the other hand, for solution 7-10, it requires the decision makers to invest more money to achieve a higher delivery rate. For all the solutions provided in each section, decision makers need to select one solution when designing a MSC network. In order to do this, these solutions can be evaluated further via the Max-Min method in order to select the best Pareto solution that has the minimum distance to the objectives' ideal values.

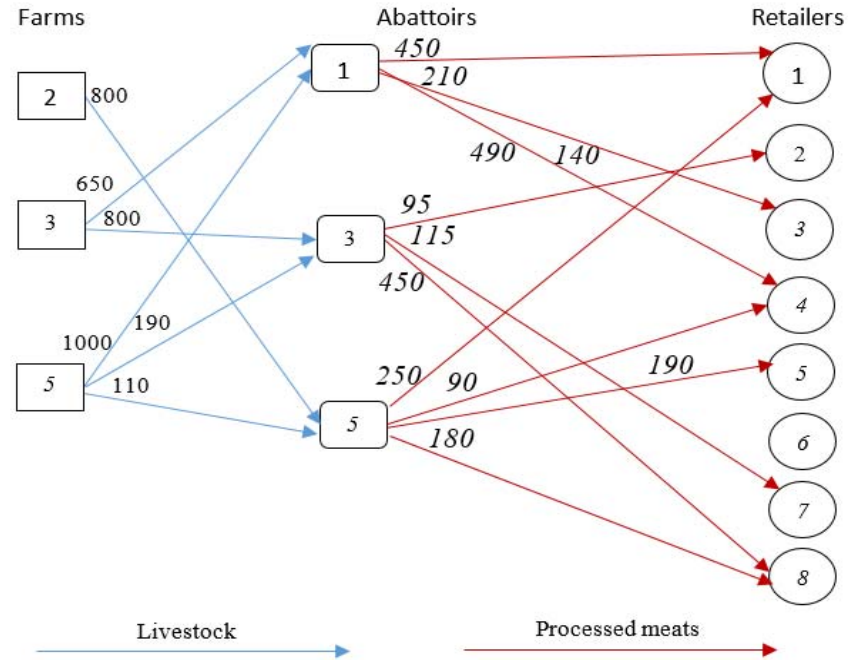

Fig. 2. The optimal design and distribution plan for the MSC. 
In this case, solution 4 was selected as the solution shown in Table $\mathrm{V}$ as it has the closest value to objectives' ideal (3.511). Therefore, compared to the LP-metrics approach, the $\varepsilon$-constraint method is more effective for this model. Based on solution 4 in Table $\mathrm{V}$, it indicates that three farms, which are located in Warwick and Leicester, were selected to supply livestock to three abattoirs, which are located in Warwick, Birmingham and Norfolk. This solution requires a minimum total transportation cost of 88,321 GBP. It yields $\mathrm{CO}_{2}$ emissions equivalent to $11050.22 \mathrm{Kg}$, and a delivery rate up to $85.8 \%$. Fig. 2 illustrates the number of the selected farms and abattoirs and the optimal flow of product quantity from farms to abattoirs and from abattoirs to retailers. It shows that farm two supplies 800 livestock to abattoir five and abattoir three supplies 95 packages of meats to retailer two as in this way it gives an optimal distribution plan.

\section{CONCLUSIONS}

This study investigated a three-echelon meat supply chain by developing a fuzzy multi-objective linear programming model aimed at the optimization of three objectives; these include the minimization of the total transportation cost and $\mathrm{CO}_{2}$ emissions $(\mathrm{Kg})$ and the maximization of the average delivery rate. Two different methods were employed to obtain the Pareto solutions. A case study was used based on the developed FMOLPM to examine the validity of the developed model. The research findings concluded that the developed FMOLPM can be useful to (i) determine the numbers of facilities with locations that should be opened to a supply chain network in response to the quantity flow of products, (ii) obtain a trade-off decision by making a comprising solution among the considered conflicting objectives. The result demonstrates that the $\varepsilon$-constraint method outperforms the LPmetrics approach to solve the developed model.

\section{REFERENCES}

[1] R. Accorsi, S. Cholette, M. Manzini, C. Pini, S. Penazzi, "The landnetwork problem: ecosystem carbon balance in planning sustainable agro-food supply chains", Journal of Cleaner Production, vol. 112, pp. 158-171, 2016.

[2] M. Fattahi, M. Mahootchi, K. Govindan, "Dynamic supply chain network design with capacity planning and multi-period pricing", Transport. Res. Part E: Logist. Transport. Rev., vol. 81, pp. 169-202, 2015.

[3] A. Rong, R. Akkerman, M. Grunow, "An optimization approach for managing fresh food quality throughout the supply chain", International Journal of Production Economics, vol. 131, pp. 421-429. 2011.

[4] V. Sahar, B. Arijit, P.J. Byrne, "A case analysis of a sustainable food supply chain distribution system-A multi-objective approach," International Journal of Production Economics, vol. 152, pp. 71-87, 2010 .

[5] L. Snyder, "Facility location under uncertainty: A review", IIE Trans, vol. 38, pp. 537-554, 2006.

[6] M.H.F. Zarandi, A.H. Sisakht, S. Davari, "Design of a closed-loop supply chain (CLSC) model using an interactive fuzzy goal programming", The International Journal of Advanced Manufacturing Technology, vol. 56, pp. 809-821, 2011.

[7] S. Liu, L.G. Papageorgiou, "Multi objective optimisation of production, distribution and capacity planning of global supply chains in the process industry," Omega vol. 41, pp. 369-382, 2013.
[8] D. Kannan, R. Khodaverdi, L. Olfat, A. Jafarian, A. Diabat, "Integrated fuzzy multi criteria decision making method and multi-objective programming approach for supplier selection and order allocation in a green supply chain", Journal of Cleaner Production vol. 47, pp. 355 367, 2013.

[9] A. Mohammed, Q. Wang, "Delivery planner for meat supply chain network under uncertainty: a multi-objective possibilistic programming approach," British Food Journal, vol. 118, -

[10] D. Peidro, J. Mula, R. Poler, J. Verdegay, "Fuzzy optimization for supply chain planning under supply, demand and process uncertainties", Fuzzy Sets System. Vol. 160, pp. 2640-2657, 2009.

[11] M. Jiménez López, M. Arenas, A. Bilbao, M.V. Rodriguez, "Linear programming with fuzzy parameters: An interactive method resolution", Eur. J. Oper. Res., vol. 177, pp. 1599-1609, 2007.

[12] HMC, UK. (2010). http://www.halalhmc.org/ , Available: http://www.halalhmc.org/test-demo.htm . (accessed October 26, 2014). 